REVISTA DE DERECHO UNED, NÚM. 27, 2021

\title{
LA PROTECCIÓN DIGITAL DEL MENOR: EL FENÓMENO DEL SHARENTING A EXAMEN
}

\author{
THE DIGITAL PROTECTION OF THE MINOR: THE SHARENTING \\ PHENOMENON UNDER CONSIDERATION
}

\author{
AinOA García GARCÍA ${ }^{1}$
}

Sumario: I. Introducción. II. El fenómeno del sharenting. II. A. El limite de edad para el acceso de los menores a Internet. II. B. El futuro Reglamento ePrivacy. II. C. La práctica del sharenting y las posibles vías de protección de los menores. II. D. La prestación del consentimiento de los menores. II. E. El derecho al olvido de los menores. II. F. El sharenting con fines lucrativos. III. La protección jurídica del menor en Internet. III. A. El concepto de minoría de edad internacional. III. B. Normativa internacional sobre la protección del menor en la Red. III. C. Nuevas vías para la protección jurídica de los menores. $I V$. La defensa del menor en la era digital. V. Conclusiones.

Resumen: En la actualidad, las redes sociales ostentan un papel fundamental en nuestra vida diaria y, en especial, en la vida de la mayoría de los menores. De hecho, nos encontramos ante el auge de un escenario particular: el sharenting, la sobreexposición por parte de los progenitores de sus hijos e hijas en las redes sociales. De este

1 Investigadora en formación. Líneas de investigación: derechos de la infancia y la adolescencia, el derecho y la política educativa, el desarrollo de proyectos culturales socioeducativos y la historia de la educación musical. Graduada en Derecho por la Universitat de València, máster en Acceso a la Abogacía por la Universidad Nacional de Educación a Distancia y titulada superior en Musicología por el Conservatorio Superior de Música "Joaquín Rodrigo» de Valencia. Actualmente cursando el Máster Interuniversitario en Investigación en Derecho de la Cultura por la Universidad Carlos III de Madrid y la Universidad Nacional de Educación a Distancia y el Título Superior de Música en la especialidad de Pedagogía por el Conservatorio Superior de Música «Joaquín Rodrigo» de Valencia. 
modo, el presente artículo pretende examinar la protección del derecho al honor, a la intimidad personal y familiar y a la propia imagen de los menores en este contexto digital internacional. Concretamente, esta investigación estudiará la normativa estadounidense, europea y española en la materia, con el fin de analizar la actual regulación del fenómeno y elaborar un examen crítico para la defensa del interés de tan vulnerable sector de la población.

Palabras clave: Sharenting, protección digital del menor, riegos de Internet, derechos personalísimos, patria potestad.

Abstract: Nowadays, social networks play a fundamental role in our daily life and, especially, in the lives of most minors. In fact, we are facing the rise of a particular scenario: sharenting, the overexposure by parents of their sons and daughters on social networks. Thus, this article aims to examine the protection of the rights to honor, personal and family privacy and of the image of minors within this international digital context. Specifically, this research will study the US, European and Spanish regulations concerning this matter, in order to analyze the current regulation of the phenomenon and prepare a critical examination to defend the interest of such a vulnerable sector of the population.

Key words: Sharenting, digital protection of minors, Internet risks, personal rights, parental authority.

Recepción original:10-7-2020

Aceptación original:11-10-2020

\section{INTRODUCCIÓN}

Actualmente, nos encontramos ante una nueva era: la era digital. La sociedad de la información y la comunicación ha supuesto grandes retos para el legislador. La masiva utilización de las redes sociales por parte de los menores ha incrementado exponencialmente los riesgos a los que se exponen en Internet. Estas plataformas digitales se han posicionado como uno de los medios de comunicación más populares del ciberespacio, llegando a superar en algunos casos los 29 millones de usuarios en nuestro país, constituyendo los niños, niñas y adolescentes el mayor porcentaje de perfiles de este tipo de plataformas ${ }^{1}$. Precisamente, el acceso a Internet se produce a edades

1 We are social y Hootsuite, "Digital 2020: Informe sobre el uso del móvil, internet y las redes sociales", Agencia creativa WE ARE SOCIAL. Disponible online en: 
cada vez más tempranas ${ }^{2}$. A este contexto debemos añadirle el incremento de los menores influencers, dicho en otras palabras, aquellos menores que reciben una contraprestación, ya sea económica o en especie, por compartir contenido en las redes sociales ${ }^{3}$. Por tanto, en estos casos, el acceso a las plataformas digitales por parte de niños, niñas y adolescentes es de forma consciente, voluntaria y retribuida.

Una situación diferente es la cuestión del sharenting. La palabra anglosajona sharenting proviene de la fusión de las palabras share (compartir) y parenting (crianza) ${ }^{4}$. El término hace referencia a un fenómeno en auge: se trata de la exposición en redes sociales de todo tipo de información personal de menores, especialmente fotografías y vídeos, por parte de sus progenitores. Esta práctica se ha vuelto tan habitual que, desde 2016, sharenting ha sido incluida en algunos diccionarios $^{5}$. Al igual que los menores influencers, las familias también pueden percibir una contraprestación por compartir contenido de sus hijos e hijas en dichas plataformas, pudiendo llegar a convertirse en la principal fuente de ingresos del núcleo familiar6.

Todas estas circunstancias hacen que pueda llegar a verse vulnerado el derecho al honor, a la intimidad personal y familiar y, en especial, a la propia imagen de este sensible sector de la población.

A pesar de que sería interesante examinar en más detalle el primer supuesto, donde los menores son los que voluntariamente acceden a la Red, en el artículo nos centraremos en el segundo escenario, donde los progenitores son los gestores de la identidad digital ${ }^{7}$

https://datareportal.com/reports/digital-2020-spain [Fecha de consulta: 23 de marzo de 2020].

2 UNICEF, El Estado Mundial de la Infancia 2017: Niños en un mundo digital, División de Comunicaciones de UNICEF, Nueva York, 2017.

3 López-Villafranca, P. y Olmedo-Salar, S., "Menores en YouTube, ¿ocio o negocio? Análisis de casos en España y EUA”, El profesional de la información, vol. 28, núm. 5, 2019.

4 Ammerman YeBra, J., "El régimen de prestación del consentimiento para la intromisión en los derechos de la personalidad de los menores. Especial referencia al fenómeno del sharenting", Actualidad Jurídica Iberoamericana, núm. 8 (bis), 2018.

5 En el diccionario Collins English Dictionary podemos encontrar la siguiente definición: "The habitual use of social media to share news, images, etc of one's children". Disponible online en: https://www.collinsdictionary.com/ [Fecha de consulta: 24 de marzo de 2020].

6 GutiérRez MAYO, E., "Instamamis: la exposición de menores en las redes sociales por sus progenitores. Análisis civil", Portal Jurídico Notariosyregistradores. com. Disponible online en: https://www.notariosyregistradores.com/web/ [Fecha de consulta: 24 de marzo de 2020].

7 Entendida como "la expresión electrónica del conjunto de rasgos con los que una persona, física o jurídica, se individualiza frente a los demás. Los cimientos de la identidad digital se hallan tanto en la creación como en la recopilación de dichos 
de sus hijos e hijas, sin tener estos últimos, en muchas ocasiones, la capacidad madurativa necesaria para poder decidir sobre la difusión de determinados aspectos de su vida privada.

\section{EL FENÓMENO DEL SHARENTING}

\section{II.A. El límite de edad para el acceso de los menores a Internet.}

La Agencia Española de Protección de Datos ofrece una definición de redes sociales considerándolas como servicios prestados a través de Internet que consienten a los usuarios "generar un perfil público, en el que plasmar datos personales e información de uno mismo, disponiendo de herramientas que permiten interactuar con

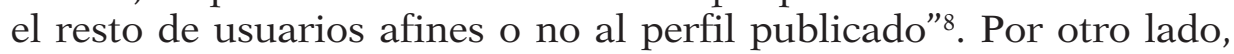
en el ámbito europeo, podemos citar la definición del Grupo de Trabajo del Artículo 29, el cual recogió en su Opinión 5/20099 que "los Servicios de Red Social pueden definirse, generalmente, como plataformas de comunicación en línea, que consienten a los individuos crear redes de usuarios que comparten intereses comunes".

Cada país de la Unión Europea establece una edad límite para el acceso a Internet. Con la entrada en vigor del Reglamento General de Protección de Datos 2016/679 del Parlamento Europeo y el Consejo, del 27 de abril de 2016, relativo a la protección de las personas físicas en lo que respecta al tratamiento de sus datos personales y a la libre circulación de estos datos (en adelante RGPD), se pretende superar el mosaico normativo irregular que provoca la existencia de diferencias importantes en la protección de los derechos de los ciudadanos ${ }^{10}$. De esta forma, el RGPD es una revisión unificada de las bases legales del modelo europeo de protección de datos que se aplica a toda la ciudadanía europea y a todas las entidades que operan en la Unión, con independencia de dónde tengan su sede. De este modo, su alcance territorial es lo suficientemente amplio como

atributos identificativos por su titular o por terceros". FERNÁNDEZ BURGUEÑo, P., "Aspectos jurídicos de la identidad digital y la reputación online”, adComunica: Revista de Estrategias, Tendencias e Innovación en Comunicación, núm. 3, 2012, pág. 127.

${ }^{8}$ AEPD e INTECO, Estudio sobre la privacidad de los datos personales y la seguridad de la información en las redes sociales online, División de Comunicaciones de AEPD e INTECO, Madrid, 2009, pág. 7.

9 Opinión 5/2009 sobre las redes sociales en línea del Grupo de Trabajo del Artículo 29 del 12 de junio de 2009.

10 Punto III del preámbulo de la Ley Orgánica 3/2018, de 5 de diciembre, de Protección de Datos Personales y Garantía de los Derechos Digitales. 
para extenderse a responsables de datos (por ejemplo, prestadores de servicios en línea) de cualquier lugar del mundo.

Por otro lado, conforme al principio de seguridad jurídica, el RGPD permite que sus normas sean especificadas o restringidas por el Derecho de los Estados miembros en la medida en que sea necesario por razones de coherencia y para que las disposiciones nacionales sean comprensibles para sus destinatarios. De esta suerte, el primer apartado del artículo 8 del RGPD indica:

"1. Cuando se aplique el artículo 6, apartado 1, letra a), en relación con la oferta directa a niños de servicios de la sociedad de la información, el tratamiento de los datos personales de un niño se considerará lícito cuando tenga como mínimo 16 años. Si el niño es menor de 16 años, tal tratamiento únicamente se considerará lícito si el consentimiento lo dio o autorizó el titular de la patria potestad o tutela sobre el niño, y solo en la medida en que se dio o autorizó. Los Estados miembros podrán establecer por ley una edad inferior a tales fines, siempre que esta no sea inferior a 13 años".

Este precepto incluye por primera vez en el ámbito europeo una referencia explícita a la protección de datos de los menores de edad. Ni la Directiva 95/46/CE, de 24 de octubre de 1995, ni la Directiva 2002/58/CE ${ }^{11}$, de 12 de julio de 2002, recogían mención expresa al caso de los niños, niñas y adolescentes. En efecto, el RGPD se aplica a todos los menores residentes en la Unión, independientemente de si son o no europeos y de su situación legal o jurídica en Europa. De hecho, el primer apartado del artículo 4 del RGPD, al referirse a los "interesados" no alude a ninguna diferenciación o discriminación por razón de nacionalidad o situación. En el caso de los niños, niñas y adolescentes esta aclaración tiene especial relevancia en relación con una situación cada vez más numerosa y preocupante, la de los menores extranjeros no acompañados, tema de enorme importancia en nuestros días ${ }^{12}$.

En cuanto al legislador español, este aspecto está regulado por el artículo 7 de la Ley Orgánica 3/2018, de 5 de diciembre, de protección de datos personales y garantía de los derechos digitales (en lo sucesivo LOPDGDD), donde se establece:

"1. El tratamiento de los datos personales de un menor de edad únicamente podrá fundarse en su consentimiento cuando sea mayor de catorce años. Se exceptúan los supuestos en que la ley exija la

11 Modificada por la Directiva 2009/136/CE

12 Piñar Real, A., "Tratamiento de datos de menores de edad", en Piñar Mañas, J. L., Álvarez Caro, M. y Recio Gayo, M., Reglamento general de protección de datos. Hacia un nuevo modelo europeo de privacidad, Ed. Reus, Madrid, 2016.

(C) UNED. Revista de Derecho UNED, núm. 27, 2021 
asistencia de los titulares de la patria potestad o tutela para la celebración del acto o negocio jurídico en cuyo contexto se recaba el consentimiento para el tratamiento. 2. El tratamiento de los datos de los menores de catorce años, fundado en el consentimiento, solo será lícito si consta el del titular de la patria potestad o tutela, con el alcance que determinen los titulares de la patria potestad o tutela".

Por consiguiente, el consentimiento del menor de edad para el tratamiento de sus datos personales solamente podrá ejercitarse cuando tenga una edad superior a los catorce años, salvo en los supuestos que recoja la ley.

Con respecto a la forma en la verificación de la edad, el segundo apartado del artículo 8 del RGPD impone que en el caso de menores de dieciséis años (catorce años en nuestro país):

"2. El responsable del tratamiento hará esfuerzos razonables para verificar en tales casos que el consentimiento fue dado o autorizado por el titular de la patria potestad o tutela sobre el niño, teniendo en cuenta la tecnología disponible".

De manera que, tras el análisis de este precepto no encontramos referencia alguna al consentimiento del menor para el tratamiento de sus datos personales cuando, como vimos anteriormente, ya se considera que puede consentir por sí mismo. Según Piñar Real ${ }^{13}$, en esta situación podríamos acudir al apartado 4 del artículo 13 del Real Decreto 1720/2007, de 21 diciembre, por el que se aprueba el Reglamento de desarrollo de la Ley Orgánica 15/1999, de 13 de diciembre, de protección de datos de carácter personal:

"4. Corresponderá al responsable del fichero o tratamiento articular los procedimientos que garanticen que se ha comprobado de modo efectivo la edad del menor y la autenticidad del consentimiento prestado en su caso, por los padres, tutores o representantes legales".

Si examinamos la disposición derogatoria única de la LOPDGDD se indica que:

"1. Sin perjuicio de lo previsto en la disposición adicional decimocuarta y en la disposición transitoria cuarta, queda derogada la Ley Orgánica 15/1999, de 13 de diciembre, de Protección de Datos de Carácter Personal. 2. Queda derogado el Real Decreto-ley 5/2018, de 27 de julio, de medidas urgentes para la adaptación del Derecho español a la normativa de la Unión Europea en materia de protección de datos. 3. Asimismo, quedan derogadas cuantas disposiciones de

13 Piñar Real, A., "Los menores de edad en el Reglamento General de Protección de Datos", Portal jurídico elderecho.com. Disponible online en: https://elderecho.com/los-menores-de-edad-en-el-reglamento-general-de-proteccion-de-datos [Fecha de consulta: 23 de abril de 2020]. 
igual o inferior rango contradigan, se opongan, o resulten incompatibles con lo dispuesto en el Reglamento (UE) 2016/679 y en la presente ley orgánica".

Con esto, la autora entiende que esta previsión no le es de aplicación al artículo 13 del Real Decreto, ya que no contradice ni es incompatible con esta normativa, sino que la completa. Así, sin llegar a ser una obligación, sería conveniente que los responsables realicen esos procedimientos que garanticen que han comprobado de modo efectivo la edad del usuario. Para Zabía de la Mata"14, "si el responsable del fichero articula estos procedimientos, los documenta debidamente y comprueba efectivamente que esto se cumple, no se le puede hacer responsable, por ejemplo, del hecho de que el menor de edad haya falsificado su carné o haya fotocopiado el de su padre o tutor sin su consentimiento". Por consiguiente, en el caso de las redes sociales y los menores de edad, aunque por ahora no se lleven a cabo de forma exhaustiva, si la empresa articula los procedimientos adecuados que garanticen que se ha comprobado de modo efectivo la edad del menor y la autenticidad del consentimiento prestado por el titular de la patria potestad o tutela, no se le podría hacer responsable ${ }^{15}$.

\section{II.B. El futuro Reglamento ePrivacy.}

Por otro lado, es fundamental hablar acerca del Reglamento sobre el respeto de la vida privada y la protección de los datos personales en el sector de las comunicaciones electrónicas, más conocido como Reglamento ePrivacy, con el que la Unión Europea pretende reforzar la privacidad de los ciudadanos en Internet, regular la protección de datos de un modo más estricto y dar forma al llamado Mercado Único Digital ${ }^{16}$. Lo que se pretende es que el Reglamento ePrivacy (lex specialis) concrete lo estipulado en el RGPD (lex generalis) ${ }^{17}$.

14 ZabÍA de la Mata, J., "Consentimiento para el tratamiento de datos de menores de edad", en Zabía de la Mata, J. (Coord.), Protección de Datos: Comentarios al Reglamento, Ed. Lex Nova, Valladolid, 2008, pág. 189.

15 En nuestro país no se especifican cuáles son estos procedimientos por ley. No es el caso de la normativa estadounidense que será abordada más adelante.

16 Propuesta de Reglamento del Parlamento Europeo y del Consejo sobre la privacidad y las comunicaciones electrónicas presentada por la Comisión Europea el 10 de enero de 2017 (COM/2017/010 final - 2017/03 (COD)).

17 IONOS, "ePrivacy: ¿qué novedades trae el nuevo Reglamento de la UE?", Digital Guide IONOS. Disponible online en: https://www.ionos.es/digitalguide/paginasweb/derecho-digital/eprivacy-reglamento-sobre-privacidad-electronica-en-la-eu/ [Fecha de consulta: 15 de mayo de 2020]. 
Una vez se apruebe y entre en vigor este Reglamento, derogará la vigente Directiva 2002/58/CE sobre privacidad y comunicaciones electrónicas, incorporada al ordenamiento jurídico español mediante la Ley 34/2002, de 11 de julio, de servicios de la sociedad de la información y de comercio electrónico. Mientras que la Directiva se aplica al tratamiento de datos en relación con la prestación de los tradicionales servicios de comunicaciones electrónicas, conforme a lo dispuesto en la Propuesta del Reglamento ePrivacy se amplía el ámbito al tratamiento de datos por parte de empresas relacionadas con el ámbito digital ${ }^{18}$. Por lo tanto, este Reglamento es el que más afectará a las empresas con respecto a cualquier normativa anterior sobre privacidad. En cuanto al ámbito territorial, al igual que hace el RGPD, el Reglamento ePrivacy se aplicará a los datos derivados de la prestación y utilización de servicios de comunicaciones electrónicas de usuarios finales, personas físicas o jurídicas, que se encuentren en la Unión Europea, independientemente de que la compañía se encuentre o no en la Unión ${ }^{19}$.

La tramitación del Reglamento ePrivacy está resultando de lo más tortuosa y conflictiva, ya que, tras un total de trece versiones de borradores, en noviembre de 2020 fue rechazada la última versión por el Comité de Representantes Permanentes de los Gobiernos de los Estados miembros en el Consejo de la Unión Europea. Con todo, se espera que a lo largo de este 2021 se retome el diálogo referente a este importante texto legal ${ }^{2021}$.

Para acabar, el Reglamento ePrivacy no contiene disposiciones específicas en materia de minoría de edad. De esta suerte, podemos estimar que como propuesta de lege ferenda, en futuros borradores del Reglamento se podría tener en consideración, siendo

18 Artículo 1 primer apartado de la Propuesta de Reglamento del Parlamento Europeo y del Consejo sobre la privacidad y las comunicaciones electrónicas presentada por la Comisión Europea el 10 de enero de 2017 (COM/2017/010 final 2017/03 (COD)).

19 Artículo 3 de la Propuesta de Reglamento del Parlamento Europeo y del Consejo sobre la privacidad y las comunicaciones electrónicas presentada por la Comisión Europea el 10 de enero de 2017 (COM/2017/010 final - 2017/03 (COD)).

20 Viafirma, "Protección de datos en Europa 2020: el Reglamento ePrivacy y nuevos cambios para la RGPD”, Viafirma. Disponible online en: https://www.viafirma.com/blog-xnoccio/es/proteccion-datos-europa/ [Fecha de consulta: 15 de mayo de 2020].

${ }^{21}$ HEBERGEMENTWEBS, "El reglamento ePrivacy 2021: estado del arte de la UE", HEBERGEMENTWEBS. Disponible online en: https://www.hebergementwebs.com/tutoriales/el-reglamento-eprivacy-2021-estado-del-arte-de-la-ue [Fecha de consulta: 5 de mayo de 2021]. 
una nueva vía para proteger, todavía más, los derechos de los menores en la Red.

\section{II.C. La práctica del sharenting y las posibles vías de protección de los menores.}

Como adelantamos en la introducción de esta investigación, el sharenting es la práctica por la cual los progenitores publican datos personales de los menores en las redes sociales, por lo general, sin su consentimiento. Esta práctica tiene como principal consecuencia la creación de una identidad digital prematura. Sales ${ }^{22}$ concluye que, en Estados Unidos, el 92\% de los menores de edad tiene ya una identidad digital en los primeros dos años de vida. Este alarmante dato puede ser perfectamente extrapolable a nuestro país, donde cada día más, podemos observar la sobreexposición que hacen de sus hijos e hijas algunas personas. Esta práctica se puede dar incluso antes del nacimiento del menor. De hecho, se ha acuñado otro término que se conoce como nacimiento digital, que se emplea en los casos donde las parejas publican fotografías o vídeos de las ecografías de sus hijos e hijas. Según diversos estudios, se ha calculado que un $23 \%$ de los progenitores realizan esta acción ${ }^{23}$. Además, la Universidad de San Francisco en colaboración con las Universidades de Michigan y Washington ${ }^{24}$, ha publicado un estudio sobre el sharenting que muestra que en Estados Unidos el 56\% de los progenitores comparte información potencialmente vergonzosa de sus hijos e hijas, el 51\% aporta datos que pueden llevar a localizar al menor y el 27\% cuelga fotografías directamente inapropiadas.

En nuestro ordenamiento jurídico, el derecho al honor, a la intimidad personal y familiar y a la propia imagen está recogido de forma explícita en el artículo 18 de nuestra Constitución:

"1. Se garantiza el derecho al honor, a la intimidad personal y familiar y a la propia imagen. [...] 4. La ley limitará el uso de la informática para garantizar el honor y la intimidad personal y familiar de los ciudadanos y el pleno ejercicio de sus derechos".

22 Sales, N. J., American Girls: Social Media and the Secret Lives of Teenagers, Penguin Random House LLC, Nueva York, 2017.

23 Instituto InTERnacional de Estudios SOBRe la FAmilia, Sharenting. La sobreexposición de los hijos en las redes sociales, The Family Watch, Madrid, 2019, pág. 2.

24 Hiniker, A., Schoenebeck, S. Y. y Kientz, J. A., "Not at the dinner table: parents and children's perspectives on family technology rules", en CSCW, Papers of the 19th ACM Conference on Computer-Supported Cooperative Work and Social Computing, CSCW, San Francisco, 2016, pág. 1385. 
Por su parte, el Tribunal Europeo de Derechos Humanos (de ahora en adelante TEDH) se pronuncia sobre este aspecto desde la perspectiva del artículo 8 del Convenio para la protección de los derechos humanos y de las libertades fundamentales, elaborado en Roma el 4 de noviembre de 1950, que protege el derecho al respeto a la vida privada y familiar, al domicilio y a la correspondencia.

Asimismo, el legislador español ha reconocido estos derechos en la Ley Orgánica 1/1982, de 5 de mayo, sobre protección civil del derecho al honor, a la intimidad personal y familiar y a la propia imagen, cuyo artículo 1 apartado primero establece que "será protegido civilmente frente a todo género de intromisiones ilegítimas". Dichos derechos son, como expresa su apartado tercero, irrenunciables, inalienables e imprescriptibles, hasta el punto de que la renuncia a la protección prevista en la ley será nula, sin perjuicio de los supuestos de autorización o consentimiento a los que se refiere el artículo 2 de esta ley.

Los menores de edad, por el mero hecho de serlo, tienen igualmente reconocidos los derechos al honor, a la intimidad personal y familiar y a la propia imagen, por cuanto se tratan de derechos fundamentales inherentes a toda persona, con independencia de su condición, edad o capacidad de obrar ${ }^{25}$. La Convención de los Derechos del Niño de Nueva York aprobada en la Asamblea General de Naciones Unidas el 20 de noviembre de 1989 y ratificada por España el 30 de noviembre de 1990 no se recogen expresamente estos derechos, pero su artículo 16 establece:

"16. Ningún niño será objeto de injerencias arbitrarias o ilegales en su vida privada, su familia, su domicilio o su correspondencia ni de ataques ilegales a su honra y a su reputación. El niño tiene derecho a la protección de la ley contra esas injerencias o ataques".

De esta forma, encontramos una relación de estos derechos de la personalidad con el artículo 16 dado que forman parte de la vida privada, intimidad y honor del menor.

Por otro lado, la Ley Orgánica 1/1996, de 15 de enero, de protección jurídica del menor ${ }^{26}$ (en lo sucesivo LOPJM) sí que regula en el primer apartado de su artículo 4 que los menores tienen derecho al

25 Velilla Antolín, N., "Ejercicio del derecho a la imagen de los menores de edad e incapaces. Redes sociales y prensa”, Blog jurídico de la magistrada Natalia Velilla Antolín. Disponible online en: https://todahistoriatienedosversiones.wordpress. com/2018/11/03/ejercicio-del-derecho-a-la-imagen-de-los-menores-de-edad-e-incapacesredes-sociales-y-prensa/ [Fecha de consulta: 28 de abril de 2020].

26 Modificada por la Ley 26/2015, de 28 de julio, de Modificación del Sistema de Protección a la Infancia y a la Adolescencia. 
honor, a la intimidad personal y familiar y a la propia imagen. Igualmente, se ha de apuntar también que el segundo apartado de la disposición establece concretamente:

"2. La difusión de información o la utilización de imágenes o nombre de los menores en los medios de comunicación que puedan implicar una intromisión ilegítima en su intimidad, honra o reputación, o que sea contraria a sus intereses, determinará la intervención del Ministerio Fiscal, que instará de inmediato las medidas cautelares y de protección previstas en la Ley y solicitará las indemnizaciones que correspondan por los perjuicios causados".

En este sentido, el tercer apartado define lo que ha de entenderse por "intromisión ilegítima" de estos derechos, que no es otra cosa que "cualquier utilización de su imagen o su nombre en los medios de comunicación que pueda implicar menoscabo de su honra o reputación, o que sea contraria a sus intereses incluso si consta el consentimiento del menor o de sus representantes legales".

De modo que nuestra legislación protege a los menores de las intromisiones ilegítimas a su derecho al honor, a la intimidad personal y familiar y a la propia imagen, mediante la intervención del Ministerio Fiscal ${ }^{27}$, incluso contra la voluntad de los titulares de la patria potestad o tutela.

\section{II.D. La prestación del consentimiento de los menores.}

Por otro lado, ¿cuándo estamos ante un ejercicio legítimo del derecho a la propia imagen de los menores? La respuesta la hallamos en el artículo tercero de la Ley Orgánica 1/1982, que establece que el consentimiento de los menores e incapaces deberá prestarse por ellos mismos si sus condiciones de madurez lo permiten. Pero ¿cuándo entendemos que un menor es maduro para consentir? Aquí

27 A este respecto, cabe mencionar la Instrucción 2/2006, de 15 de marzo, sobre el Fiscal y la protección del derecho al honor, intimidad y propia imagen de los menores. En dicha instrucción, el Fiscal General del Estado expone, con el propósito de cumplir las obligaciones que en relación con los derechos al honor, intimidad y propia imagen de los menores impone nuestro ordenamiento jurídico al Ministerio Público, una serie de prescripciones que los señores Fiscales atenderán. Entre ellas, podemos subrayar la legitimación directa y autónoma del Fiscal para proteger los derechos de los menores al honor, la intimidad y la propia imagen en los casos en que el menor afectado tenga progenitores en pleno uso de las facultades inherentes a la patria potestad, y que -sin que concurra conflicto de intereses con el menorsean contrarios a que se entablen acciones en defensa del mismo. 
nos hallamos ante un concepto jurídico indeterminado que nos lleva al examen del caso concreto ${ }^{28}$.

En este sentido, hemos de considerar el artículo 7 de la LOPDGDD y el artículo 8 del RGPD, cuya idea fundamental era que los menores a partir de los catorce años podrían otorgar libremente su consentimiento para la difusión de su imagen, sin que sea preciso contar con el consentimiento de sus representantes legales. Esta autonomía de la voluntad reconocida al menor de edad no impide la aplicación del artículo 4 de la Ley Orgánica 1/1996 cuando nos encontremos ante una intromisión ilegítima del derecho a la imagen del menor, puesto que, en ese caso, se podrá actuar contra cualquier imagen que dañe objetivamente al menor, aun cuando para su difusión se haya contado con su consentimiento y con el de sus progenitores ${ }^{29}$.

Continuando con esta idea, si tenemos en cuenta que la legislación en materia de menores obliga a que los mayores de doce años sean oídos tanto en el ámbito familiar como en cualquier procedimiento administrativo, judicial o de mediación en que estén afectados, podríamos llegar a pensar que también podrían oírse en relación con los derechos personalísimos y, sobre todo, con el de la propia imagen. Sin embargo, en el caso de los mayores de doce años, estos no podrán prestar su consentimiento, sino que deberán ser autorizados por sus representantes legales. En cambio, por su grado de madurez sí que se les permitiría ser oídos y, en su caso, decidir, incluso contra la voluntad de sus padres, si su imagen puede ser utilizada y cómo debe efectuarse esa utilización. En los casos de los menores de doce años, por tanto, habrá que estudiar el caso concreto para considerar si tienen madurez suficiente como para enervar el consentimiento previamente dado por sus representantes legales, atendiendo al interés superior del menor ${ }^{30}$.

Visto el marco jurídico sobre el ejercicio del derecho a la imagen de los menores, es conveniente analizar lo que sucede cuando, los titulares de la patria potestad o tutela, en las edades en las que los menores aún no pueden prestar su consentimiento, hacen un mal uso de los datos personales de sus hijos, hijas o tutelados.

28 Velilla Antolín, N., "Patria potestad digital: menores e Internet", Blog jurídico de la magistrada Natalia Velilla Antolín, en Aliaga Casanova, A. (Coord.), Libro de familia: revista jurídica de Derecho de familia, Asociación de jueces y magistrados Francisco de Vitoria, Madrid, 2007.

${ }_{29}$ Vidal CASERo, M. C., "La evolución legislativa de la protección del menor, la defensa de sus derechos y la atención a su salud", DS: Derecho y salud, vol. 10, núm. 2, 2002.

30 Velilla Antolín, N., "Ejercicio del derecho a la imagen ...", ob. cit. [Fecha de consulta: 30 de abril de 2020]. 
Si nos retrotraemos a la Ley Orgánica 1/1982, su artículo 2 establece que la protección de los derechos de la personalidad "quedará delimitada por las leyes y por los usos sociales atendiendo al ámbito que, por sus propios actos, mantenga cada persona reservado para sí misma o su familia". De esta forma, la disposición contiene los parámetros generales para medir si una intromisión se considera o no ilegítima. De esto podemos extraer que no toda práctica de sharenting la entenderemos como intromisión ilegítima en los derechos de la personalidad del menor, pues en especial los usos sociales han modelado el concepto de privacidad que tenemos tanto de nuestra imagen como de determinados aspectos de nuestra intimidad personal y familiar ${ }^{31}$.

Desde el punto de vista jurisprudencial, la Sentencia de la Audiencia Provincial de Lugo 57/201732, nos sirve de ejemplo de cómo los usos sociales pueden determinar que una cierta conducta sea considerada constitutiva de intromisión ilegítima en los derechos de la personalidad de los menores. En este caso la madre y demandante entendía que se estaban vulnerando los derechos a la intimidad y propia imagen de sus hijos al publicar la abuela fotografías y comentarios de ellos en la red social Facebook. Aunque el fallo establece que no se ha producido una vulneración de dichos derechos, reconoce que la cuestión litigiosa puede llevar a duda por la falta de regulación sobre este tema y la concurrencia del interés superior del menor. La sentencia basa su razonamiento en que el acceso a la cuenta de Facebook de la abuela no era público, por lo que solo podían acceder a la información un grupo reducido de personas. No obstante, aclara que la conclusión a la que habrían llegado los magistrados habría sido diferente si se tuviera constancia de que los datos de los menores hubieran sido expuestos a cualquier usuario de la plataforma. Por ello, que exista intromisión podrá depender no solo del tipo de información subida a las redes sociales, sino también de las configuraciones de privacidad, de la permanencia temporal de dicha información, e incluso del uso que posteriormente haga el propio menor de su identidad, ya sea a la edad de catorce años o una vez alcanzada la mayoría de edad.

Otra sentencia de gran relevancia es la dictada por la Sala Primera del Tribunal Supremo, de fecha 30 de junio de $2015^{33}$, en relación con el derecho a la propia imagen de los menores. En el fundamento segundo se señala que el derecho al honor, a la intimidad

31 AMMERMAN YeBRA, J., ob. cit.

32 ECLI: ES:APLU:2017:98.

33 ECLI: ES:TS:2015:2856. 
personal y familiar y a la propia imagen, "en el caso de menores tiene como presupuesto el hecho de que siempre que no medie el consentimiento de los padres o representantes legales de los menores con la ausencia del Ministerio Fiscal, la difusión de cualquier imagen de éstos ha de ser reputada contraria al ordenamiento jurídico (SSTS de 19 de noviembre de 2008; 17 de diciembre 2013; 27 de enero 2014, entre otras)". Por lo tanto, a la vista de dicha sentencia podemos concluir que compartir algún dato personal de los menores en las redes sociales forma parte de la patria potestad. Si esa información se ha autorizado por los progenitores, siempre que ambos ostenten la patria potestad del menor y no vulnere ningún derecho de la personalidad de este, no debería haber mayor problema. Pero ¿qué sucede si existe un conflicto entre el menor y el titular de su patria potestad en relación con la protección de datos? Ante esta situación debería prevalecer, como siempre, el principio del interés superior del menor. Asimismo, se pondrían en funcionamiento las vías previstas en cada país para velar por dicho interés. En España disponemos del artículo 163 del Código Civil:

"Siempre que en algún asunto el padre y la madre tengan un interés opuesto al de sus hijos no emancipados, se nombrará a éstos un defensor que los represente en juicio y fuera de él. Se procederá también a este nombramiento cuando los padres tengan un interés opuesto al del hijo menor emancipado cuya capacidad deban completar. Si el conflicto de intereses existiera solo con uno de los progenitores, corresponde al otro por Ley y sin necesidad de especial nombramiento representar al menor o completar su capacidad".

Puede afirmarse que el segundo apartado de este artículo no sería operativo en la protección del menor en Internet ya que, aunque la guarda del menor se haya atribuido a una parte, la potestad parental la tienen y ejercen ambos de forma compartida, por lo que la decisión de publicar datos personales del mismo la deben tomar ambos progenitores sin perjuicio de la ruptura de su relación de pareja. Esta idea la observamos, por ejemplo, en la Sentencia 360/2017 de la Sección 18 de la Audiencia Provincial de Barcelona ${ }^{34}$ :

"El derecho a la propia imagen es un derecho fundamental y la decisión de publicar una fotografía del hijo en una red social pertenece a la esfera de la responsabilidad parental compartida por ambos progenitores, no a la guarda. Los padres como titulares de la patria potestad tienen el deber y la responsabilidad de proteger la imagen de sus hijos menores de edad y como señala el Tribunal Supremo será preciso el acuerdo de ambos progenitores para poder publicar imágenes del hijo común en las redes sociales. En todo caso los pa-

34 ECLI: ES:APB:2017:3677. 
dres deberán evitar en interés del menor una sobreexposición del hijo en estos ámbitos."

Otra cuestión es qué hacer cuando los padres no están de acuerdo, y, sobre todo, cuando esa disconformidad se da entre parejas separadas o divorciadas. La Sentencia de la Sección Primera de la Audiencia Provincial de Pontevedra, de 4 de junio de $2015^{35}$, ha resuelto esta cuestión. En ella se explica el procedimiento a seguir en nuestro país, correspondiente a un procedimiento de jurisdicción voluntaria al amparo del artículo 156 del Código Civil:

"En caso de desacuerdo, cualquiera de los dos podrá acudir al Juez, quien, después de oír a ambos y al hijo si tuviera suficiente madurez y, en todo caso, si fuera mayor de doce años, atribuirá la facultad de decidir al padre o a la madre. Si los desacuerdos fueran reiterados o concurriera cualquier otra causa que entorpezca gravemente el ejercicio de la patria potestad, podrá atribuirla total o parcialmente a uno de los padres o distribuir entre ellos sus funciones. Esta medida tendrá vigencia durante el plazo que se fije, que no podrá nunca exceder de dos años".

Así, en estos procedimientos, el juez resolverá atendiendo al alcance de la publicación y, sobre todo, si con esa publicación se está perjudicando el interés superior del menor o se le somete a una sobreexposición en la Red.

\section{II.E. El derecho al olvido de los menores.}

En otro orden de cosas, podemos preguntarnos sobre el derecho de supresión, también conocido como Habeas Data o "derecho al olvido" ${ }^{36}$, de los menores de edad en Internet. Si bien el derecho de supresión ya se había incluido en el artículo 12 de la Directiva 95/46/ $\mathrm{EC}^{37}$ o en el artículo 9 del Convenio del Consejo de Europa para la Protección de las Personas con respecto al Tratamiento Automati-

35 ECLI: ES:APPO:2015:1123.

36 Se toma como referencia la definición recogida en Simón CASTELlano, P., "El carácter relativo del derecho al olvido en la red y su relación con otros derechos, garantías e intereses legítimos", en Corredoira y ALFonso, L. y Cotino Hueso, L., Libertad de expresión e información en Internet. Amenazas y protección de los derechos personales, Centro de Estudios Políticos y Constitucionales, Madrid, 2013, pág. 452: "La voz derecho al olvido es una garantía del individuo frente al tratamiento masivo y descontrolado de datos personales que puede darse en Internet. Se puede definir como la facultad de suprimir, cancelar e impedir la divulgación de los datos personales cuando estos no son necesarios para cumplir la finalidad por la que fueron recabados y divulgados, o cuando existen otras finalidades legítimas que prevalecen".

37 "Los Estados miembros garantizarán a todos los interesados el derecho de obtener del responsable del tratamiento: [...] (b) en su caso, la rectificación, la supresión 
zado de Datos Personales del 28 de enero de $1981^{38}$, el "derecho al olvido" en Internet se hizo patente en 2014 gracias a la popular sentencia sobre Google España de 13 de mayo (asunto C-131/12) del Tribunal de Justicia de la Unión Europea (en adelante TJUE) ${ }^{39}$. En dicha sentencia se dictamina que el "derecho al olvido" permite a un sujeto "restringir o poner fin a la diseminación de aquellos de sus datos personales que considere perjudiciales o contrarios a sus intereses". Además, con este pronunciamiento el Alto Tribunal concreta de forma definitiva las responsabilidades de los buscadores de Internet en relación con la protección de los datos personales, y asimismo otorga tutela ante la situación de indefensión generada, en este asunto, al no haber admitido la compañía Google que le era aplicable la normativa española y europea reguladora de la materia ${ }^{40}$.

El RGPD contiene en su artículo 17 el derecho de supresión, con la adhesión del "derecho al olvido" entre paréntesis. Esta formulación refleja la divergencia de opiniones respecto a si estos derechos se diferencian o si, en efecto, significan lo mismo ${ }^{41}$. Para el Supervisor Europeo de Protección de Datos (a partir de ahora SEPD), el artículo 17 fortalece el derecho de supresión al convertirlo en "el derecho al olvido para permitir una ejecución más efectiva de este derecho en el entorno digital" 42 . De este modo, podemos considerar que el artículo no crea un nuevo derecho, sino que detalla el derecho de supresión. De hecho, en el primer apartado del artículo 17 se estipula que "el interesado tendrá derecho a obtener sin dilación indebida del responsable del tratamiento la supresión de los datos personales que le conciernan". El precepto continúa indicando las diversas circunstancias en las que se podrá ejercer este derecho, como por ejemplo cuando los datos ya no son necesarios para los fines para los que fueron recogidos o cuando los datos personales han

o el bloqueo de los datos cuyo tratamiento no se ajuste a las disposiciones de la presente Directiva, en particular a causa del carácter incompleto o inexacto de los datos".

38 "Podrán preverse por la ley restricciones en el ejercicio de los derechos a que se refieren los párrafos b), c) y d) del artículo 8 para los ficheros automatizados de datos de carácter personal que se utilicen con fines estadísticos o de investigación científica, cuando no existan manifiestamente riesgos de atentado a la vida privada de las personas concernidas".

39 ECLI:EU:C:2014:317.

40 Dopazo Fraguío, P., "La protección de datos en el derecho europeo principales aportaciones doctrinales y marco regulatorio vigente. (Novedades del Reglamento General de Protección de Datos)", Revista española de derecho europeo, núm. 68, 2018.

41 Lievens, E. y Vander Maelen C., "El derecho al olvido de los niños: ¿dejar atrás el pasado y aceptar el futuro?”, Latin American Law Review, núm. 2, 2018.

42 Punto 146 del Dictamen del SEPD de 7 de marzo de 2012 sobre el paquete legislativo de reforma de la protección de datos. 
sido tratados ilícitamente. Por lo tanto, esta obligación corresponde al "responsable del tratamiento", que según el apartado séptimo del artículo 4 del RGPD es "la persona física o jurídica, autoridad pública, servicio u otro organismo que, solo o junto con otros, determine los fines y medios del tratamiento".

Otra innovación del RGPD es la relevancia que le da al "derecho al olvido" de los menores. Como señalamos anteriormente, los niños, niñas y adolescentes pueden no ser plenamente conscientes de que sus datos personales están siendo tratados, ni de las personas físicas o jurídicas que los tratan. De modo que, a medida que crezcan, es posible que ya no quieran estar vinculados con información compartida sobre ellos ${ }^{43}$. Esta misma idea está recogida en el considerando 65 del RGPD:

"Este derecho es pertinente en particular si el interesado dio su consentimiento siendo niño y no se es plenamente consciente de los riesgos que implica el tratamiento, y más tarde quiere suprimir tales datos personales, especialmente en Internet. El interesado debe poder ejercer este derecho aunque ya no sea un niño".

Por lo que se refiere al ámbito territorial del "derecho al olvido", De Miguel Asensio ${ }^{44}$ indica que el ámbito de aplicación espacial de la legislación europea sobre protección de datos suscita un especial interés, pues se trata de un derecho reconocido en la Unión Europea, pero no en otros, de modo que una eventual pretensión de imponerlo en relación con servicios de prestadores de terceros Estados a usuarios situados también en terceros Estados suscitaría dificultades obvias.

Mediante la sentencia del 24 de septiembre de 2019 (asunto C-507/17) ${ }^{45}$, el TJUE responde a una cuestión prejudicial planteada en el marco de un proceso judicial que tuvo su origen en la sanción impuesta a Google por la autoridad francesa de protección de datos (la Commission Nationale de l'Informatique et des Libertés, en adelante CNIL) ante su negativa de eliminar los datos de una persona física, que había ejercido su derecho de supresión, en todas las extensiones de nombre de dominio de su motor de búsqueda en todo el mundo. La CNIL exigió en su momento a Google que, ante una solicitud de eliminación de datos, debía impedir su localización desde cualquier versión del buscador, no solo desde las de dominio euro-

43 BESSANT, C., "Sharenting: balancing the conflicting rights of parents and children", Communications Law, vol. 23, núm. 1, 2018.

44 De Miguel Asensio, P. A., "Ámbito espacial del derecho al olvido. Las conclusiones en el asunto C-507/17, Google”, La Ley Unión Europea, núm. 67, 2019.

45 ECLI:EU:C:2019:772. 
peo. Sin embargo, el gigante tecnológico se limitó a suprimir los enlaces exclusivamente de las extensiones del buscador en los Estados miembros. En respuesta a la cuestión planteada, el TJUE concluye que, en virtud del Derecho de la Unión el buscador no tiene obligación de proceder a la supresión de los datos de todos los dominios, es decir, su obligación se circunscribe al ámbito de los países de la Unión Europea, ya que en los Estados no miembros puede no reconocerse el "derecho al olvido" o puede que, al regular la relación entre este derecho y la libertad de información o de expresión, los ordenamientos de esos otros territorios contemplen una prevalencia distinta entre los derechos afectados. De este modo, el TJUE determina que el Derecho de la Unión no puede imponer su modelo de derecho de supresión a otros Estados no miembros. No obstante, matiza que tampoco lo prohíbe. Por lo tanto, una autoridad de control o judicial de un Estado miembro sigue siendo competente para realizar, de conformidad con los estándares nacionales de protección de los derechos fundamentales, una ponderación entre el derecho del interesado al respeto de la protección de los datos personales que le conciernan, y el derecho a la libertad de información y, al término de esta ponderación, exigir, en su caso, al gestor del motor de búsqueda que proceda a retirar los enlaces de todas las versiones de dicho motor ${ }^{46}$.

En relación con el tema que nos ocupa, en aquellas circunstancias en las que los menores se ven afectados por la información que comparten sus progenitores, el derecho de supresión puede ser ejercido por parte de un menor que pueda considerarse competente para hacerlo, o bien por parte de un adulto cuando se trata de información que se trató durante su infancia. A este respecto, cabe plantear dos salvedades diferentes ${ }^{47}$.

En primer lugar, según el artículo 2 del RGPD, en aquellas circunstancias en las que la información compartida por los padres se considere que está dentro del ámbito familiar, el RGPD y, por tanto, el derecho de supresión, no se aplicarían. Tendríamos pues que analizar el caso concreto para determinar si nos encontramos ante esta situación o no. Como expresa el considerando 18 del RGPD, ciertas actividades en redes sociales podrían ampararse bajo esta excepción familiar, pero otras seguramente no.

46 Colomina CID, A., "La justicia europea delimita el alcance territorial del derecho al olvido", CMS Law.Tax Publicaciones. Disponible online en: https://cms.law/es/ esp/publication/la-justicia-europea-delimita-el-alcance-territorial-del-derecho-al-olvido [Fecha de consulta: 24 de mayo de 2020].

47 Lievens, E. y Vander Maelen C., ob. cit. 
“18. El presente Reglamento no se aplica al tratamiento de datos de carácter personal por una persona física en el curso de una actividad exclusivamente personal o doméstica y, por tanto, sin conexión alguna con una actividad profesional o comercial. Entre las actividades personales o domésticas cabe incluir la correspondencia y la llevanza de un repertorio de direcciones, o la actividad en las redes sociales y la actividad en línea realizada en el contexto de las citadas actividades. No obstante, el presente Reglamento se aplica a los responsables o encargados del tratamiento que proporcionen los medios para tratar datos personales relacionados con tales actividades personales o domésticas".

Si examinamos el segundo apartado de este considerado, llegamos a la conclusión que en aquellas circunstancias en las que los datos compartidos por los titulares de la patria potestad o tutela se consideren que están dentro de una actividad exclusivamente personal o doméstica, el RGPD sí que se aplicaría para las plataformas de red social.

Sin embargo, podemos considerar lo expuesto en el Dictamen del Grupo de Trabajo del Artículo 29, del 12 de junio de 2009, sobre las redes sociales en línea ${ }^{48}$. En dicho documento se destaca cómo gran parte de los usuarios de las redes sociales se mueve dentro de una esfera personal, familiar o doméstica, aplicándose lo que denomina como "exención doméstica". El Dictamen precisa también en qué circunstancias las actividades de un usuario no están cubiertas por la "exención doméstica":

"Las actividades de algunos usuarios de SRS pueden superar una actividad puramente personal o doméstica, por ejemplo cuando el SRS se utiliza como una plataforma de colaboración para una asociación o una empresa. Si un usuario de SRS actúa en nombre de una empresa o de una asociación o utiliza el SRS principalmente como una plataforma con fines comerciales, políticos o sociales, la exención no se aplica. En este caso, el usuario asume la plena responsabilidad de un responsable del tratamiento de datos que revela datos personales a otro responsable del tratamiento de datos (SRS) y a terceros (otros usuarios de SRS o incluso, potencialmente, a otros responsables del tratamiento de datos que tienen acceso a ellos). En tales circunstancias, el usuario necesita el consentimiento de las personas interesadas u otra base legítima que figure en la Directiva relativa a la protección de datos. Generalmente, el acceso a los datos de un usuario (datos del perfil, mensajes, historias...) se limita a los contactos elegidos. Sin embargo, en algunos casos, los usuarios pueden adquirir un gran número de contactos terceros y no conocer a algunos de ellos. Un gran número de contactos puede indicar que no se

48 Dictamen 5/2009 WP 163 sobre las redes sociales en línea del Grupo de Trabajo sobre Protección De Datos del Artículo 29, adoptado el 12 de junio de 2009.

(C) UNED. Revista de Derecho UNED, núm. 27, 2021 
aplica la excepción doméstica y el usuario podría entonces ser considerado como un responsable del tratamiento de datos".

Por tanto, no entrarían dentro de la "exención doméstica" las actividades que tengan como fin la colaboración con una asociación o una empresa; las actividades con fines comerciales, políticos o sociales; cuando el acceso a la información del perfil se amplía hasta más allá de una serie de contactos seleccionados y cuando no se garantizan los derechos de terceros, particularmente en relación con datos sensibles.

Asimismo, el Comité Europeo de Protección de Datos, con respecto a la videovigilancia, que establece en sus Directrices 3/2019 sobre el procesamiento de datos personales a través de dispositivos de vídeo ${ }^{49}$ :

"Por lo tanto, según lo considerado por el Tribunal de Justicia de la Unión Europea, la llamada 'exención del hogar' debe 'interpretarse en relación solo con actividades que se llevan a cabo en el curso de la vida privada o familiar de las personas, lo que claramente no es el caso con el procesamiento de datos personales consistente en la publicación en Internet para que esos datos sean accesibles a un número indefinido de gente"”.

Además, la sentencia del Tribunal de Justicia de la Unión Europea de 6 de noviembre de $2003^{50}$, que, si bien es anterior al RGPD, manifiesta lo siguiente:

"En cuanto a la excepción prevista en el segundo guion del artículo 3, apartado 2, de la Directiva 95/46, en el duodécimo considerando de esta última, relativo a dicha excepción, se citan como ejemplos de tratamiento de datos efectuado por una persona física en el ejercicio de actividades exclusivamente personales o domésticas la correspondencia y la llevanza de un repertorio de direcciones. En consecuencia, esta excepción debe interpretarse en el sentido de que contempla únicamente las actividades que se inscriben en el marco de la vida privada o familiar de los particulares; evidentemente, no es éste el caso de un tratamiento de datos personales consistente en la difusión de dichos datos por Internet de modo que resulten accesibles a un grupo indeterminado de personas".

Por ende, los tres documentos consideran que la "exención familiar" no se puede aplicar a las situaciones en las que se publican datos, fotografías, vídeos o audios en las redes sociales para un número indefinido de gente.

49 Guidelines 3/2019 on processing of personal data through video devices, publicada por el Comité Europeo de Protección de Datos el 29 de enero de 2020.

50 ECLI:EU:C:2003:596. 
En segundo lugar, los menores que no se consideran legalmente competentes para ejercer su derecho de supresión, y tienen que depender de los titulares de la patria potestad o tutela para hacerlo, evidentemente se encontrarán en una situación más complicada. Quizás el primer aparado del artículo 80 del RGPD pueda proporcionarnos una solución para esta cuestión:

"1. El interesado tendrá derecho a dar mandato a una entidad, organización o asociación sin ánimo de lucro que haya sido correctamente constituida con arreglo al Derecho de un Estado miembro, cuyos objetivos estatutarios sean de interés público y que actúe en el ámbito de la protección de los derechos y libertades de los interesados en materia de protección de sus datos personales, para que presente en su nombre la reclamación, y ejerza en su nombre los derechos contemplados en los artículos 77, 78 y 79, y el derecho a ser indemnizado mencionado en el artículo 82 si así lo establece el Derecho del Estado miembro".

Por consiguiente, un menor, un familiar, o incluso un tercero, podría acudir a entidades que presten servicios de protección infantil o a otras organizaciones que representen los intereses de los niños y niñas para que estas presenten una solicitud en su nombre.

Por lo que respecta a la puesta en práctica del "derecho al olvido", cuando un menor o su representante quieran ejercerlo, es preciso que el responsable del tratamiento sea contactado mediante una solicitud ${ }^{51}$. Posteriormente, conforme el tercer apartado del artículo 12 del RGPD, el responsable del tratamiento debe proporcionar información sobre las acciones que se tomaron con respecto a la solicitud, sin ninguna demora indebida y en cualquier caso dentro del mes siguiente a la recepción de esta. Si el responsable de los datos decide no tomar medidas, el apartado cuarto del mismo precepto establece que:

“4. [...] le informará sin dilación, y a más tardar transcurrido un mes de la recepción de la solicitud, de las razones de su no actuación y de la posibilidad de presentar una reclamación ante una autoridad de control y de ejercitar acciones judiciales".

Esto quiere decir que en el caso de que el interesado (menor o su representante) no esté satisfecho con dicha decisión, es posible presentar una queja ante la autoridad de protección de datos competente $^{52}$, que investigará el caso y lo evaluará. Igualmente, también tiene derecho a un recurso judicial efectivo cuando considere que

51 Coвacho López, Á., "Reflexiones en torno a la última actualización del derecho al olvido digital", Revista de Derecho Político UNED, núm. 104, 2019.

52 Artículo 77 del RGPD. 
sus derechos consagrados en el RGPD han sido violados, pudiendo ejercer su derecho de supresión ante un tribunal nacional. No obstante, si esta acción tampoco resultara satisfactoria, en un futuro las disputas podrían terminar en el TJUE o, dentro del contexto de los artículos 8 o 10 de la Convención Europea de Derechos Humanos, podrían terminar en el TEDH ${ }^{53}$.

Por último, considero que el "derecho al olvido" únicamente puede ser de utilidad si los interesados conocen la existencia de dicho derecho. Una posible solución sería la mejora de educación digital de los menores, recogida en el artículo 83 de la LOPDGDD, con respecto a las redes sociales y al tratamiento de sus datos personales:

“1. El sistema educativo garantizará la plena inserción del alumnado en la sociedad digital y el aprendizaje de un uso de los medios digitales que sea seguro y respetuoso con la dignidad humana, los valores constitucionales, los derechos fundamentales y, particularmente con el respeto y la garantía de la intimidad personal y familiar y la protección de datos personales. Las actuaciones realizadas en este ámbito tendrán carácter inclusivo, en particular en lo que respecta al alumnado con necesidades educativas especiales. Las Administraciones educativas deberán incluir en el diseño del bloque de asignaturas de libre configuración la competencia digital a la que se refiere el apartado anterior, así como los elementos relacionados con las situaciones de riesgo derivadas de la inadecuada utilización de las TIC, con especial atención a las situaciones de violencia en la red

2. El profesorado recibirá las competencias digitales y la formación necesaria para la enseñanza y transmisión de los valores y derechos referidos en el apartado anterior.

3. Los planes de estudio de los títulos universitarios, en especial, aquellos que habiliten para el desempeño profesional en la formación del alumnado, garantizarán la formación en el uso y seguridad de los medios digitales y en la garantía de los derechos fundamentales en Internet.

4. Las Administraciones Públicas incorporarán a los temarios de las pruebas de acceso a los cuerpos superiores y a aquéllos en que habitualmente se desempeñen funciones que impliquen el acceso a datos personales materias relacionadas con la garantía de los derechos digitales y en particular el de protección de datos."

De hecho, la disposición final décima de la LOPDGDD incorpora una modificación puntual de la Ley Orgánica 6/2006, de 3 de mayo, de Educación (en adelante, LOE). En esta ley educativa se

53 Lievens, E. y Vander Maelen C., ob. cit. 
incluye en el artículo 2, apartado primero, letra h), que, dentro de los fines que orientan el sistema educativo, se añade expresamente el siguiente:

"La capacitación para garantizar la plena inserción del alumnado en la sociedad digital y el aprendizaje de un uso seguro de los medios digitales y respetuoso con la dignidad humana, los valores constitucionales, los derechos fundamentales y, particularmente, con el respeto y garantía de la intimidad individual y colectiva".

\section{II.F. El sharenting con fines lucrativos.}

Para acabar, como habíamos adelantado en la introducción de esta investigación, el sharenting puede ejercerse por mero placer, pero a veces se ejercita con un fin indudablemente lucrativo. Las familias pueden obtener ingresos muy cuantiosos por la publicidad de determinados productos que, en ocasiones, pueden llegar a convertirse en la principal fuente de ingresos del núcleo familiar. ¿Estaríamos ante un caso de explotación de menores cuando los progenitores obtienen ingresos económicos mediante el volcado de datos de sus hijos e hijas en la Red? La respuesta, según Florit Fernández ${ }^{54}$, sería afirmativa por considerar lo expuesto en el artículo 6 del Estatuto de los Trabajadores, los artículos 31 y 32 de la Convención de los Derechos del Niño y la Directiva 94/33 del Consejo relativa a la protección de los jóvenes en el trabajo. Esta última es de gran interés ya que excluye de la prohibición general del trabajo infantil a aquellos supuestos en los que se contrate al menor para "actividades de carácter cultural, artístico, deportivo o publicitario", siempre que se posea la autorización necesaria de la Autoridad Laboral ${ }^{55}$. Por tanto, en el supuesto de los menores influencers pasivos, podría entenderse como actividad de carácter artístico y publicitario, puesto que los progenitores reciben remuneración económica, siendo indispensable la autorización de la Autoridad Laboral.

54 FloRIT FERNÁNDEZ, C., " "Sharenting» y límites de la patria potestad”, Superbia Jurídico. Disponible online en: https://superbiajuridico.es/texts/sharenting-y-limitesde-la-patria-potestad/ [Fecha de consulta: 11 de mayo de 2020].

55 Al igual que el artículo 9 de la Ley 20/2007, de 11 de julio, del Estatuto del trabajo autónomo. 


\section{LA PROTECCIÓN JURÍDICA DEL MENOR EN INTERNET}

\section{III.A. El concepto de minoría de edad internacional.}

Con carácter previo a analizar la protección jurídica del menor en Internet, debemos definir qué es la minoría de edad para el Derecho Internacional.

La legislación nacional de cada país es la encargada de determinar el límite que existe entre la minoría y la mayoría de edad. Por tanto, no existe una definición unitaria del concepto de "menor". Los textos legales, nacionales e internacionales, aplicables en ordenamiento jurídico en el ámbito de la protección del menor, manifiestan la diversidad de acepciones que posee ${ }^{56}$.

El primer artículo de la Convención de Derechos del Niño, de 20 de noviembre de 1989, señala que "se entiende por niño todo ser humano menor de dieciocho años de edad, salvo que, en virtud de la Ley que le sea aplicable, haya alcanzado antes la mayoría de edad". En la misma línea encontramos en el artículo 1 de la LOPJM; el artículo 1 del Convenio de La Haya sobre competencia de autoridades, ley aplicable y reconocimiento de decisiones en materia de adopción, de 15 de noviembre de 1965, y el artículo 3 del Convenio de La Haya relativo a la protección del niño y a la cooperación en materia de adopción internacional, de 29 de mayo de 1993. Por otro lado, al igual que el Convenio Europeo de Estrasburgo, de 25 de enero de 1996, sobre el ejercicio de los derechos de los niños, el artículo 2 del Convenio de La Haya relativo a la competencia, la ley aplicable, el reconocimiento, la ejecución y la cooperación en materia de responsabilidad parental y de medidas de protección de los niños, de 19 de octubre de 1996, indica que dicho convenio se aplica a "los niños a partir de su nacimiento y hasta que alcancen la edad de dieciocho años".

Sin embargo, no todos los convenios consideran esta edad como el punto de inflexión entre la minoría y la mayoría de edad. El artículo 1.a). del Convenio Europeo de Luxemburgo, de 20 de mayo de 1980, relativo al reconocimiento y la ejecución de decisiones en materia de custodia de menores, así como al restablecimiento de dicha custodia, considera como menor a "una persona, cualquiera que sea su nacionalidad, siempre que su edad sea inferior a los dieciséis años y que no tenga derecho a fijar su residencia, según la Ley de su

56 Esplugues Mota, C., "Capacidad y régimen de incapacidades", en EsPlugues Mota, C., Iglesias Buhigues, J. L. y Palao Moreno, G. Derecho Internacional Privado, $13^{\mathrm{a}}$ ed., Ed. Tirant Lo Blanch, Valencia, 2019. 
residencia habitual o de su nacionalidad o según la legislación interna del Estado requerido". En los mismos términos encontramos el artículo 4 del Convenio de La Haya sobre los aspectos civiles de la sustracción internacional de menores, de 25 de octubre de 1980, y el Convenio hispano-marroquí sobre asistencia judicial, reconocimiento y ejecución de resoluciones judiciales en materia de derecho de custodia y derechos de visita y devolución de menores, de 30 de mayo de 1997.

En cambio, por el contrario, en otros convenios la edad es mayor. Sirvan como ejemplo los Convenios de La Haya del 2 de octubre de 1973 en materia de alimentos, donde se establece la edad de veintiún años (Convenio sobre Ley Aplicable a las Obligaciones Alimenticias y Convenio sobre Reconocimiento y Ejecución de Resoluciones relativas a las Obligaciones Alimenticias).

Además de estas nociones de "menor", diversos convenios que vinculan a nuestro país incorporan nociones propias. En el artículo 12 del Convenio de La Haya sobre competencia de autoridades y ley aplicable en materia de protección de menores, de 5 de octubre de 1961, se señala que "se entenderá por "menor» toda persona que tenga la calidad de tal, tanto según la ley interna del Estado del que es nacional como según la ley interna del Estado de su residencia habitual". De esta manera, el precepto establece una definición acumulativa de concepto de "menor", según la ley de su nacionalidad y según la ley de su residencia habitual ${ }^{57}$.

Por consiguiente, desde el punto de vista numérico, podemos decir que no existe unanimidad en aquellos convenios internacionales que abordan al menor y su protección. De este modo, la minoría de edad puede oscilar entre los dieciséis y veintiún años.

\section{III.b. Normativa internacional sobre la protección del menor en la Red.}

A continuación, haremos un repaso al marco jurídico aplicable a la protección de los menores en Internet, haciendo especial hincapié en la salvaguarda del derecho al honor, a la intimidad personal y familiar y de la propia imagen. Para contar con una visión global del actual contexto que nos atañe, se analizará el ámbito internacional y el europeo.

57 BORRÁs RodríGUEZ, A., "El interés del menor como factor de progreso y unificación del derecho internacional privado", Revista Jurídica de Catalunya, núm. 4, 1994.

(C) UNED. Revista de Derecho UNED, núm. 27, 2021 


\section{Organización de las Naciones Unidas}

El primer paso para la protección del menor en el siglo XX se dio con la Declaración de Ginebra sobre los Derechos del Niño, de 24 de septiembre de 1924, que pretendió establecer una síntesis de los derechos de los menores. Contiene cinco artículos donde se expresan los principios básicos de la protección de la infancia. Concretamente, en su primer punto se hace referencia al desarrollo integral de la personalidad del menor: "El niño debe ser puesto en condiciones de desarrollarse normalmente desde el punto de vista material y espiritual".

Después de la Segunda Guerra Mundial, los Estados fundadores de la ONU se convencieron de la necesidad de proteger los derechos humanos fundamentales que deben ser reconocidos a toda persona $^{58}$. Fruto de esta tarea legislativa internacional fue la Declaración de los Derechos Humanos, de 10 de diciembre de 1948. En la Declaración aparece una referencia expresa a los menores en el segundo apartado de su artículo 25, donde se dispone que "la maternidad y la infancia tienen derecho a cuidados y asistencia especiales. Todos los niños, nacidos de matrimonio o fuera de matrimonio, tienen derecho a igual protección social". Por otro lado, en relación con nuestro estudio podemos destacar su artículo 12, que también se aplicaría a los menores de edad:

"Nadie será objeto de injerencias arbitrarias en su vida privada, su familia, su domicilio o su correspondencia, ni de ataques a su honra o a su reputación. Toda persona tiene derecho a la protección de la ley contra tales injerencias o ataques".

Más adelante, la Declaración de los Derechos del Niño, de 20 de noviembre de 1959, amplía a diez artículos los derechos del menor e insiste en la protección de la personalidad de este, encuadrándola en la importancia del hogar y de la familia. En esta normativa se recogen los derechos y libertades fundamentales de la infancia, como la igualdad, la protección especial o la calidad de vida ${ }^{59}$.

Por lo que respecta a la Convención de los Derechos del Niño, de 20 de noviembre de 1989, podemos afirmar que fue el paso más importante a escala global para disponer de un marco jurídico, político y social sólido en la defensa de los derechos de la infancia ya que, entre otras obligaciones, exige a los Estados miembros de la ONU desplegar un ordenamiento jurídico interno acorde con los princi-

58 Ocón Domingo, J., "Normativa internacional de protección de la infancia", Cuadernos de Trabajo Social, vol. 19, 2006.

59 Vidal Casero, M. C., ob. cit. 
pios y el articulado de esta Convención ${ }^{60}$. En este sentido, el documento recuerda y complementa los diez principios de la Declaración de los Derechos del Niño de 1959. Además, estudiando la Convención de 1989, podemos encontrar ya en su Preámbulo una referencia a la Declaración de 1959: "El niño, en su falta de madurez física y mental, necesita de protección y cuidados especiales, incluso a la debida protección legal, tanto antes como después del nacimiento".

De su articulado podemos destacar en primer lugar la disposición tercera, donde se alude al ya mencionado interés superior del menor en relación con la toma de decisiones sobre los niños, niñas y adolescentes donde siempre deberá prevalecer. En relación con el tema que nos ocupa, más adelante, los artículos 32, 33, 34, 35, 36 y 39 garantizan el desarrollo pleno de la personalidad del menor y la protección contra toda forma de explotación. Por último, el precepto que tiene una mayor relación con nuestro estudio es el 16, en el que se expresa que:

“1. Ningún niño será objeto de injerencias arbitrarias o ilegales en su vida privada, su familia, su domicilio o su correspondencia ni de ataques ilegales a su honra y a su reputación. 2. El niño tiene derecho a la protección de la ley contra esas injerencias o ataques".

Para que las Naciones Unidas puedan controlar que todos los Estados miembros cumplen con lo acordado en la Convención, los Estados firmantes deben remitir cada cinco años una serie de informes sobre las medidas adoptadas y sobre los progresos que han realizado en relación con la protección del menor ${ }^{61}$. En este sentido, existe un órgano encargado de controlar la protección de los menores por parte de los Estados miembros. Este órgano es el Comité de los Derechos del Niño que desempeña, entre otras, las siguientes funciones: invitar a los organismos especializados, al Fondo de las Naciones Unidas para la Infancia y a otros órganos competentes que considere apropiados a que proporcionen asesoramiento especializado sobre la aplicación de la Convención en los sectores que son de incumbencia; recomendar a la Asamblea General que pida al Secretario general que efectúe, en su nombre, estudios sobre cuestiones concretas relativas a los derechos del niño, y

60 Bonal i Sarró, X., "Los derechos de la infancia en el siglo XXI", Revista Servicios Sociales y Política Social, núm. 90, 2010.

61 Artículo 44 de la Convención de los Derechos del Niño del 20 de noviembre de 1989.

(C) UNED. Revista de Derecho UNED, núm. 27, 2021 
formular sugerencias y recomendaciones generales basadas en la información recibida ${ }^{62}$.

\section{Unión Europea y Consejo de Europa}

Europa se unió a la tarea iniciada por la Organización de Naciones Unidas en busca de la protección integral y del libre desarrollo del menor. Conviene destacar, en primer lugar, el Convenio para la Protección de los Derechos Humanos y de las Libertades Fundamentales de 1950, considerado como el primer texto europeo en el que se consagra la tutela de la vida privada, derecho que regula, como vimos anteriormente, en su precepto octavo.

Igualmente, en el ámbito comunitario debe reseñarse lo dispuesto en la Carta Europea de Derechos del Niño (Resolución del Parlamento Europeo A3-0172/92 de 8 de julio de 1992) que declara que: "Todo niño tiene derecho a no ser objeto por parte de un tercero de intrusiones injustificadas en su vida privada, en la de su familia, ni a sufrir atentados ilegales contra su honor". Además, en relación con el fondo de este estudio, esta Resolución establece que: “Todo niño tiene derecho a ser protegido contra la utilización de su imagen de forma lesiva para su dignidad".

Por otra parte, debemos citar la Carta de los Derechos Fundamentales de la Unión Europea, de 7 de diciembre de 2000 (2000/C $364 / 01$ ), cuyo artículo séptimo prevé que "toda persona tiene derecho al respeto de su vida privada y familiar, de su domicilio y de sus comunicaciones". Además, el artículo octavo se pronuncia de este modo sobre la protección de los datos de carácter personal:

"1. Toda persona tiene derecho a la protección de los datos de carácter personal que la conciernan. 2. Estos datos se tratarán de modo leal, para fines concretos y sobre la base del consentimiento de la persona afectada o en virtud de otro fundamento legítimo previsto por la ley. Toda persona tiene derecho a acceder a los datos recogidos que la conciernan y a su rectificación. 3. El respeto de estas normas quedará sujeto al control de una autoridad independiente".

Desde la entrada en vigor del Tratado de Lisboa el 1 de diciembre de 2009, la Carta goza de un estatuto jurídico equiparable al de los tratados y obliga, tanto a la Unión como a los Estados miembros, a proteger los derechos consagrados en la Carta cuando apliquen el Derecho de la Unión Europea. Además, la Carta de los

62 Artículos 43 y 45 de la Convención de los Derechos del Niño del 20 de noviembre de 1989 . 
Derechos Fundamentales contiene las primeras referencias a los derechos del niño en el ámbito constitucional de la Unión ${ }^{63}$. A su vez, la Carta incluye una disposición específica sobre los derechos del niño ${ }^{64}$ que articula los tres principios básicos de dichos derechos: el derecho a expresar libremente su opinión en función de su edad y su madurez, el derecho a que su interés superior constituya una consideración primordial en todo acto que les concierna y el derecho a mantener relaciones personales y contactos directos, de forma periódica, con sus progenitores.

Hay que apuntar también que el Tratado de Lisboa introdujo importantes modificaciones institucionales, procedimentales y constitucionales en la Unión, modificando el Tratado de la Unión Europea y el anterior Tratado de la Comunidad Europea. Estas modificaciones incrementaron la capacidad de la Unión para promover los derechos del niño, entre otros aspectos importantes, mediante la definición de la "protección de los derechos del niño" como un objetivo general de la Unión Europea y como aspecto importante de la política de relaciones exteriores de la $\mathrm{UE}^{65}$. Sin embargo, el Tratado nada dice sobre la protección específica de los derechos de la personalidad de los menores.

Derecho aplicable fuera de la Unión: Estados Unidos

Dada la globalidad del tema, trataremos de forma superficial algunos aspectos normativos que, fuera de nuestras fronteras, regulan determinados aspectos relacionados con él.

En Estados Unidos, destacamos la aprobación, en 1998, de la Children's Online Privacy Protection Act (en lo sucesivo COPPA), convirtiéndose en una de las primeras normas a nivel internacional centradas en la protección de los menores en lo que respecta al tratamiento de sus datos de carácter personal, en concreto, de los menores de trece años ${ }^{66}$.

63 Agencia de los Derechos Fundamentales de la Unión Europea, Manual de legislación europea sobre los derechos del niño, Oficina de Publicaciones de la Unión Europea, Bélgica, 2016.

64 Artículo 24 de la Carta de los Derechos Fundamentales de la Unión Europea, de 7 de diciembre de 2000 (2000/C 364/01).

65 Artículo 3 del Tratado de Lisboa del 1 de diciembre de 2009.

66 Davara Fernández de Marcos, L.: Menores en Internet y Redes Sociales: Derecho Aplicable y Deberes de los Padres y Centros Educativos. Breve referencia al fenómeno Pokémon Go, Agencia Estatal Boletín Oficial del Estado, Madrid, 2017.

(C) UNED. Revista de Derecho UNED, núm. 27, 2021 
Esta ley se aplica tanto a páginas web como a los servicios online dirigidos a menores. Entre estos servicios, la Federal Trade Commis$\operatorname{sion}^{67}$ menciona las plataformas online de videojuegos, los servicios de tiendas online, las redes sociales, los servicios de mensajería instantánea y los servicios de búsqueda geolocalizada ${ }^{68}$.

Por otro lado, la COPPA aborda exhaustivamente cada una de las obligaciones de estos operadores, de forma que apenas queda margen para una interpretación flexible de la normativa ${ }^{69}$. En este sentido, es llamativa la exigencia del consentimiento parental, ya que como requerimiento general debe obtenerse el consentimiento de los progenitores siempre de forma previa a la recolección y uso de la información personal del menor ${ }^{70}$. Además, se pide al responsable del tratamiento de datos que haga un esfuerzo razonable para obtener la verificación del consentimiento parental, teniendo en cuenta la tecnología disponible ${ }^{71}$. El apartado 312.5 de la COPPA establece una serie de mecanismos para tal fin:

“(I) Proporcionar un formulario de consentimiento para ser firmado por el progenitor y devuelto al operador por correo postal, fax o escaneo electrónico; (II) requerir a un progenitor, en relación con una transacción monetaria, que use una tarjeta de crédito, tarjeta de débito u otro sistema de pago en línea que proporcione notificación de cada transacción discreta al titular de la cuenta principal; (III) hacer que un progenitor llame a un número de teléfono gratuito con personal capacitado; (IV) hacer que un progenitor se conecte con personal capacitado a través de videoconferencia; (V) verificar la identidad de un progenitor mediante la verificación de una forma de identificación emitida por el gobierno contra las bases de datos de dicha información, donde el operador elimina la identificación del progenitor de sus registros inmediatamente después de que se complete

67 Agencia independiente del gobierno de los Estados Unidos cuya misión principal es promover los derechos de los consumidores y la eliminación y prevención de prácticas que atentan contra la libre competencia. Federal Trade Commission, "About the FTC". Disponible online en: https://www.ftc.gov/about-ftc [Fecha de consulta: 16 de mayo de 2020].

68 Azurmendi AdarRaga, A., "Derechos digitales de los menores y datos masivos. Reglamento Europeo de Protección de Datos de 2016 y la COPPA de Estados Unidos", El profesional de la información, vol. 27, núm. 1, 2018.

69 GolOB, B., "How safe are safe harbors? The difficulties of self-regulatory children's online privacy protection act programs", International journal of communication, vol. 9, 2015.

70 Cabe señalar que en Estados Unidos, cada Estado establece un límite distinto entre la minoría y la mayoría de edad. Por ejemplo, en el estado de Washington la mayoría de edad se obtiene a los dieciocho años (RCW 26.28), mientras que en el estado de Mississippi esta se alcanza a los veintiuno (Mississippi Code 1-3-27).

71 Apartado 312.5, "Parental consent", de la ley Children's Online Privacy Protection Act. 
dicha verificación o (VI) siempre que un operador que no "divulgue" (como se define el punto 312.2) la información personal de los niños pueda usar un correo electrónico junto con pasos adicionales para garantizar que la persona que da el consentimiento es el progenitor. Dichos pasos adicionales incluyen: Enviar un correo electrónico de confirmación al progenitor después de recibir el consentimiento, u obtener una dirección postal o número de teléfono del progenitor y confirmar el consentimiento del progenitor por carta o llamada telefónica. Un operador que utiliza este método debe notificar que el progenitor puede revocar cualquier consentimiento otorgado en respuesta al correo electrónico anterior".

Otra característica de la COPPA es su apuesta decidida por la responsabilidad proactiva de los operadores ${ }^{72}$. La ley es el estándar mínimo exigido, de manera que pueden aprobarse directrices de protección de la privacidad de los menores en la Red que sean aún más exigentes, y en concreto, sobre la difusión de datos, fotografías, vídeos o audios de los menores en la Red.

\section{III.C. Nuevas vías para la protección jurídica de los menores.}

El pasado 9 de junio de 2020, el Consejo de Ministros aprobó el Proyecto de Ley Orgánica de Protección Integral a la Infancia y la Adolescencia frente a la Violencia, que trata de dar respuesta a la obligación de protección de los menores de edad. Este Proyecto nació como respuesta al examen del 2018 sobre la situación de los derechos de la infancia en España del Comité de Derechos del Niño. Asimismo, esta ley incluye medidas en muchos ámbitos (prevención, actuación en el nivel educativo, apoyo familiar, servicios sociales, sanidad, regulación de la publicidad, redes sociales, justicia...), teniendo en cuenta varias de las Observaciones Generales realizadas por el Comité de Derechos del Niño de Naciones Unidas y los estándares internacionales desarrollados por el Consejo de Europa en sus distintos convenios. Además, esta nueva norma persigue establecer un nuevo paradigma de prevención y protección común en todo el territorio del Estado frente a la vulneración de derechos que significa la violencia sobre la infancia y la adolescencia.

En relación con el tema que nos ocupa, este Proyecto establece que se promoverá el buen trato, la parentalidad positiva, la adquisición de competencias emocionales, de negociación y resolución de conflictos en base a la situación y necesidades de los progenitores, o

72 Apartado 312.11, "Safe harbor programs", de la ley Children's Online Privacy Protection Act.

(C) UNED. Revista de Derecho UNED, núm. 27, 2021 
en su caso, de las personas tutoras o guardadoras o acogedoras. Asimismo, la futura ley recoge el deber de comunicación de contenidos ilícitos en Internet, es decir, toda persona, física o jurídica, que advierta la existencia de contenidos disponibles en Internet que constituyan una forma de violencia contra cualquier niño, niña o adolescente, está obligada a comunicarlo a la autoridad competente y, si los hechos pudieran ser constitutivos de delito, a las Fuerzas y Cuerpos de Seguridad, al Ministerio Fiscal o a la autoridad judicial. A su vez, esta norma regula las actuaciones públicas dirigidas a garantizar el uso seguro y responsable de Internet por parte de los niños, niñas y adolescentes, familias, personal educador y profesionales que trabajen con menores de edad. Igualmente, el Proyecto normaliza el canal específico de denuncia ante la Agencia Española de Protección de Datos para garantizar una adecuada protección del derecho fundamental a la protección de datos personales y la rápida retirada de Internet los contenidos que atenten gravemente contra el mismo. También, esta norma crea nuevos tipos delictivos para evitar la impunidad de conductas realizadas a través de medios tecnológicos y de la comunicación, que producen graves riesgos para la vida y la integridad de las personas menores edad. Por último, esta ley modifica de la Ley 15/2015, de 2 de julio, de la Jurisdicción Voluntaria para asegurar el derecho de los niños, niñas y adolescentes a ser escuchados en los expedientes de su interés, salvaguardando su derecho a la defensa, expresarse con libertad y garantizando su intimidad ${ }^{7374}$.

\section{LA DEFENSA DEL MENOR EN LA ERA DIGITAL}

Seguidamente, y tras el análisis de la legislación vigente en nuestro país, procederemos a llevar a la práctica la defensa de los derechos del menor en Internet.

73 Este estudio ha pretendido mostrar, a grandes rasgos, las futuras innovaciones y medidas del Proyecto de Ley Orgánica de Protección Integral a la Infancia y la Adolescencia frente a la Violencia que tuvieran relación directa con su finalidad, dejando para posteriores investigaciones el análisis pormenorizado de esta normativa.

${ }^{74}$ El 15 de abril del 2021, el Pleno del Congreso dio luz verde, con 268 votos a favor, 57 votos en contra y 16 abstenciones, al Proyecto de Ley Orgánica de protección integral a la infancia y la adolescencia frente a la violencia y lo remitió al Senado. LEFEBVRE, "El Pleno da luz verde al Proyecto de Ley Orgánica de protección integral a la infancia y la adolescencia frente a la violencia y lo remite al Senado", elderecho.com. Disponible online en: https://elderecho.com/el-pleno-daluz-verde-al-proyecto-de-ley-organica-de-proteccion-integral-a-la-infancia-y-la-adolescencia-frente-a-la-violencia-y-lo-remite-al-senado [Fecha de consulta: 5 de mayo de 2021]. 


\section{¿Quién decide qué se puede publicar en las redes sociales?}

Encontramos dos situaciones bien diferenciadas: 1) Menores y adolescentes que publican voluntariamente datos personales, vídeos y fotografías propias en las redes sociales. En estas situaciones el conflicto suele darse entre ellos y los titulares de la patria potestad o tutela. 2) Menores que son expuestos en las redes sociales por sus progenitores, quienes publican datos personales, vídeos y fotografías de sus hijos o hijas (sharenting). En estas situaciones el conflicto suele darse entre ellos y los titulares de la patria potestad, o entre los ambos progenitores (cuando uno publica información del menor sin consentimiento del otro).

\section{Mi hijo o hija publica contenido que considero inapropiado en las redes sociales. ¿Cómo puedo actuar?}

Para decidir qué hacer, tendremos que acudir al nivel de madurez del menor. Si actúa habitualmente con madurez, y haciendo un uso responsable de Internet y las redes sociales, lo normal es que la decisión la tome el propio menor. En cualquier caso, si los progenitores no estuvieran de acuerdo con el uso de las redes sociales por parte de su hijo o hija, al ostentar estos la patria potestad, conforme al Código Civil y siempre que se vele por el interés superior del menor, podrían decidir no autorizar este uso $^{75}$.

\section{Soy menor de edad y mis padres o tutores están publicando fotografías y vídeos míos en las redes sociales. ¿Qué puedo hacer y a quién puedo acudir?}

Si hubiera un conflicto entre la voluntad de los menores y de los titulares de la patria potestad o tutela, y en caso de que el menor considere que los progenitores no están mirando por su interés, tanto él como cualquier otra persona interesada, podrá denunciar esta situación ante la fiscalía. El Ministerio Fiscal podrá defender los intereses del menor frente a los progenitores ante los tribunales.

Además, el menor podría acudir a entidades que presten servicios de protección infantil o a otras organizaciones que representen los intereses de los niños y niñas, para que estas presenten una soli-

75 Conforme al apartado primero del artículo 155 del Código Civil: "Los hijos deben obedecer a sus padres mientras permanezcan bajo su potestad, y respetarles siempre". 
citud de supresión de datos personales en su nombre o, si el caso fue de gravedad, denunciaran la situación por él. En España cada comunidad autónoma cuenta con un servicio para la protección y atención a la infancia ${ }^{76}$, asimismo encontramos diversas entidades como Save the Children, UNICEF o Plataforma de Infancia que velan por los derechos de los menores.

\section{Tengo un conflicto con el otro titular de la patria potestad o tutela con el que estoy separado o divorciado porque publica fotografías y vídeos de nuestro hijo o hija en las redes sociales. ¿Puedo llevar a cabo alguna acción para proteger al menor?}

Si los progenitores no estuvieran de acuerdo en publicar datos personales, vídeos o imágenes de sus hijos o hijas en las redes sociales, se ejecutaría el procedimiento de jurisdicción voluntaria al amparo del artículo 156 del Código Civil. Cualquiera de los dos podría acudir al juez, quien, después de oír a ambos y al menor, si tuviera suficiente madurez, resolverá atendiendo al alcance de la publicación y, sobre todo, si con esta se está perjudicando el interés superior del menor.

\section{Soy menor de edad y quiero crearme un usuario en una red social. ¿A qué edad puedo acceder?}

Según la LOPDGDD, los menores con una edad inferior a los catorce años podrán abrirse una cuenta en una red social cuando los titulares de la patria potestad o tutela den su consentimiento expreso para que se traten sus datos personales. Sin embargo, cuando el menor tiene una edad igual o superior a los catorce años podrán abrirse una cuenta en una red social sin necesidad de consentimiento de los titulares de la patria potestad o tutela, ya que se considera que pueden decidir sobre el tratamiento de sus datos personales.

76 Véase, por ejemplo, el teléfono de atención a la infancia y adolescencia de la Comunitat Valenciana. Disponible online en: http://www.inclusio.gva.es/es/web/menor/telefono-atencion_infancia [Fecha de consulta: 28 de octubre de 2020]. 


\section{Soy abogado o abogada y se ha puesto en contacto conmigo un menor que sufre sharenting por parte de sus padres o tutores. ¿Cuál es el proceso que debo seguir ante un caso de esta índole?}

En un caso de sharenting deberíamos seguir los pasos de un procedimiento civil puesto que la tutela jurisdiccional de las situaciones subjetivas de Derecho Privado no es, por regla general, imperativa o preceptiva. Cuando no se respetan las normas de Derecho Privado, ni los tribunales tienen el deber de ejercitar su potestad jurisdiccional, ni están previstos instrumentos independientes de la voluntad de las personas afectadas para instar el ejercicio de esta potestad, excepto el deber del Ministerio Fiscal de instar el ejercicio de la misma en determinados supuestos, como en el nuestro ${ }^{77}$.

Si se plantea un caso en que las normas de Derecho Privado no son respetadas, son muy diversas las posibilidades de que sea cerrado sin que los tribunales deban ejercer su potestad jurisdiccional sobre el mismo, como la mediación, el arbitraje, la conciliación, entre otras. Ahora bien, todos estos medios de solución de controversias necesitan el concurso de voluntades de las personas afectadas. Si no existe acuerdo, la única vía para la solución de la controversia es la actuación de los tribunales y mediante el ejercicio de la potestad jurisdiccional ${ }^{78}$. Además, al establecer el acceso a los tribunales para instar el ejercicio de la potestad jurisdiccional, el Estado cumple con el reconocimiento constitucional de un derecho fundamental: el derecho a la tutela judicial efectiva recogido en el artículo 24 de nuestra Constitución ${ }^{79}$.

\section{CONCLUSIONES}

$1^{\text {a) }}$ Es indiscutible que, actualmente, Internet está presente en todos los ámbitos de nuestro día a día. Concretamente, las redes sociales se han convertido en uno de los servicios más consu-

77 Ortells Ramos, M., "Introducción", en Ortells Ramos, M. (DIR.), Derecho procesal civil, $18^{\mathrm{a}}$ ed., Ed. Thomson Reuters Aranzadi, Navarra, 2019.

78 "El ejercicio de la potestad jurisdiccional en todo tipo de procesos, juzgando y haciendo ejecutar lo juzgado, corresponde exclusivamente a los Juzgados y Tribunales determinados por las leyes, según las normas de competencia y procedimiento que las mismas establezcan”. Artículo 117 apartado tercero de la Constitución.

79 "Todas las personas tienen derecho a obtener la tutela efectiva de los jueces y tribunales en el ejercicio de sus derechos e intereses legítimos, sin que, en ningún caso, pueda producirse indefensión". Artículo 24 apartado primero de la Constitución. 
midos por la población. Los menores, como reflejo de su tiempo, se incorporan a estas plataformas a edades cada vez más tempranas. En numerosas ocasiones nuestros niños, niñas y adolescentes se ven sobreexpuestos a diversidad de perjuicios por el desconocimiento de sus riesgos. Es tarea tanto del legislador como de las empresas, proporcionar una mayor seguridad en este ámbito, informando a los titulares de la patria potestad o tutela de los medios de seguridad de los que disponen en el caso de verse vulnerados sus derechos.

$2^{a}$ ) Aunque en España disponemos de una amplia normativa jurídica, la preocupación por garantizar los derechos de las personas vinculadas a los servicios online ha aumentado considerablemente a nivel europeo, dando lugar al RGPD. Sin embargo, en la ley se deberían delimitar los procedimientos que garantizaran la comprobación de la edad del menor y la autenticidad del consentimiento prestado, ya que una laguna legal en este aspecto podría dar lugar a un abandono por parte de las plataformas de red social. En este sentido, la COPPA podría ser un modelo para el futuro Reglamento ePrivacy, ya que especifica los métodos para verificar el consentimiento parental por parte de los prestadores de servicio y promueve la autorregulación de los responsables de datos. De esta suerte, podemos considerar que este Reglamento podría ser una nueva vía para proteger, aún más, los derechos de los menores en la Red.

$\left.3^{a}\right)$ El fenómeno del sharenting es una práctica en auge que ha llegado a formar parte de nuestra cotidianeidad, puesto que es habitual observar en las redes sociales fotografías y vídeos de menores difundidos por sus progenitores. El legislador debería matizar diversas cuestiones en este aspecto, como la concreción de la edad de madurez del menor para el tratamiento de sus datos personales, si ante esta actividad deberían ser oídos y a qué edad, o quién puede denunciar un caso de sharenting para la protección del menor. Asimismo creo que estas cuestiones son clave para limitar las intromisiones ilegítimas al derecho al honor, a la intimidad personal y familiar y a la propia imagen de los menores en este contexto. Desde mi punto de vista, el ejercicio responsable de la patria potestad debería poder brindar a los menores la capacidad de crear su propia identidad digital. 
$\left.4^{a}\right)$ El derecho de supresión con respecto a menores de edad solo puede ser de utilidad si los interesados conocen la existencia de dicho derecho. Este asunto podría solucionarse mejorando la educación digital de los menores con respecto a las redes sociales y al tratamiento de sus datos personales. De hecho, sería de gran utilidad que los responsables del tratamiento de datos, en este caso las empresas de red social, facilitaran información adaptada sobre este aspecto antes de crear una cuenta en sus plataformas, además de adecuar los procedimientos para que el trámite sea más sencillo para los menores.

$\left.5^{a}\right)$ Ante una situación de sharenting donde el menor vea vulnerados sus derechos, podría acudir tanto él, como un familiar, como un tercero, a entidades que presten servicios de protección infantil $\mathrm{u}$ a otras organizaciones que representen los intereses de los niños y niñas, para que estas presenten una solicitud de supresión de datos personales en su nombre. Por tanto, la importancia, no solo del abogado, sino de todo operador jurídico, podría verse reflejada en esta situación, al aplicar la normativa vigente para velar por la salvaguarda de los derechos de los menores de edad.

$6^{\text {a) }}$ Excepto en circunstancias muy excepcionales en las que otros intereses prevalezcan, en el caso en el que un menor desee llevar a cabo su derecho de supresión, la balanza debe inclinarse hacia él, ya que la principal consideración para evaluar las solicitudes debe ser el bienestar del menor y su derecho al desarrollo y al respeto de su vida privada.

$7^{\mathrm{a}}$ ) Dado que las redes sociales pueden establecerse de forma global, la minoría de edad debería establecerse internacionalmente, o al menos la consideración de menor en la Red, ya que la protección del menor en la esfera digital varía según la edad del interesado.

$\left.8^{a}\right)$ Los esfuerzos que el legislador está haciendo en esta materia son notorios. No obstante, por lo general, el derecho siempre va detrás de la realidad en la que vive, y en este aspecto aún le queda un largo camino que recorrer para conseguir adaptarse a ella. De este modo, resulta necesario que se actualice la legislación, ya no solo comunitaria, sino también internacional, en relación con las nuevas tecnologías y, en especial, con el fenómeno del sharenting. Los aspectos esenciales de esta actualiza- 
ción serían: 1) especificar los métodos para verificar el consentimiento parental por parte de los prestadores de servicio, 2) concretar la edad o las características de un menor para que sea considerado maduro para el tratamiento de sus datos personales, 3) señalar en qué casos los menores podrían ser oídos, 4) determinar qué persona puede interponer una denuncia cuando se vulneren los derechos de la personalidad de los menores y ante quién, 5) obligar a las plataformas de red social a informar sobre el "derecho al olvido" a los menores de edad y a adecuar los procedimientos para que el trámite sea más sencillo, 6) consensuar internacionalmente la consideración de menor de edad en Internet. En este sentido, resulta fundamental que las familias, los educadores, los gobiernos y los proveedores de red social se comprometan a ejercer su responsabilidad con la construcción de un Internet más seguro para nuestros niños, niñas y adolescentes. Este colectivo no es únicamente el futuro de nuestra sociedad, sino también ciudadanos del ahora con inquietudes y derechos.

9ª El Proyecto de Ley Orgánica de Protección Integral a la Infancia y la Adolescencia frente a la Violencia será un paso adelante en la protección del derecho al honor, a la intimidad personal y familiar y a la propia imagen de los menores en las redes sociales y en los casos de sharenting 